\title{
Cyclic voltammetry for a preliminary study of appropriate electro-synthesis reactions of naphthalene derivatives
}

\author{
Roman E. Sioda · Barbara Frankowska
}

Received: 23 August 2009/Accepted: 1 September 2009/Published online: 16 September 2009

(C) Springer-Verlag 2009

\section{Erratum to: Monatsh Chem (2008) 139:881-886 \\ DOI 10.1007/s00706-008-0870-z}

In the above paper, experimental data of $\mathrm{CV}$ oxidation of catechol, presented in a paper by D. Nematollahi and R.A. Rahchamani (2002) [J. Electroanal. Chem. 520:145], were used, as a measure in estimation of electrons transferred ( $n$ values) in $\mathrm{CV}$ oxidations of naphthalene and its derivatives, i.e. the values shown in Table 3 , and cited after our paper [Sioda RE and Frankowska B (2008) J. Electroanal. Chem. 612:147].

It follows from more recent papers [1-3] concerning CV oxidation of catechol, that our earlier estimation may need to be increased by about $30-70 \%$. The proposed change may be understood, taking into account that catechol seems easily oxidizable in air, especially when dissolved.

\section{References}

1. Nematollahi D, Rafiee M (2004) J Electroanal Chem 566:31

2. Fotouhi L, Asadi S, Tammari E, Heravi MM, Nematollahi D (2008) J Iran Chem Soc 5:712

3. Nematollahi D, Mohammadi-Behzad L, Davarani SSH (2009) Electroanalysis 21:1099

The online version of the original article can be found under doi: $10.1007 / \mathrm{s} 00706-008-0870-\mathrm{z}$.

R. E. Sioda $(\square) \cdot$ B. Frankowska Department of Analytical Chemistry and Electrochemistry, Institute of Chemistry, University of Podlasie, ul. 3 Maja 54, 08-110 Siedlce, Poland

e-mail: rsioda@tlen.pl 